\title{
Factors affecting the seed-setting success of Dryas octopetala in front of Brøggerbreen (Brøgger Glacier) in the high Arctic, Ny-Ålesund, Svalbard

\author{
Naoya Wada
}

\begin{abstract}
To determine the factors restricting plant reproduction in front of a glacier, the gender expression and seed production of Dryas octopetala L. (Rosaceae) were observed, as well as the grazing pattern of reindeer on flowers, near Brøggerbreen (Brøgger Glacier), which is near Ny-Alesund $\left(78^{\circ} 55^{\prime} \mathrm{N}, 11^{\circ} 56^{\prime} \mathrm{E}\right)$, Svalbard. Three hundred shoots with flowers and flower buds were randomly tagged in early July 1996. Between then and the end of flowering in late July, $100(33 \%)$ flowers and buds were grazed by reindeer. Out of the surviving flowers, $145(76 \%)$ shoots had hermaphrodite flowers, while $45(24 \%)$ shoots had male flowers without a developed gynoecium. Male flowers, which appeared later than hermaphrodite flowers in the population, were significantly smaller than hermaphrodite flowers in dry weight. In the hermaphrodite flowers, moreover, smaller flowers showed lower dry-weight allocation to the gynoecium as compared to larger flowers. During the observation, hermaphrodite flowers did not produce any developed seeds under a natural condition ( $0 \%$ seed-set). Cross-pollinated flowers showed $8 \%$ seed-set. On the other hand, flowers which were artificially warmed in small greenhouses during the flowering period showed $60 \%$ seed-set, regardless of cross-pollination or autodeposition of pollen from anthers to stigma (self-pollination). Thus, it was found that grazing, gender variation in relation to the length of the growing season and the flower size, and - in the flowering period - low temperature rather than pollinator limitation strongly affected the seed production of $D$. octopetala in the population studied.
\end{abstract}

N. Wada, Dept. of Biosphere Science, Faculty of Science, Toyama University, Toyama 930-8555, Japan.

\section{Introduction}

Global climatic warming is expected to have a stronger impact on Arctic terrestrial ecosystems than on lower latitudinal ecosystems (Maxwell 1992). Climatic warming in the Arctic will promote deglaciation, exposing bare ground in front of glaciers. To understand ecological succession in deglaciated lands, it is important to clarify how spores or seeds invade deglaciated locations and what factors limit the seed production of plants found around glaciers.

Environmental conditions in the high Arctic are extremely severe for the growth and reproduction of tundra plants (Kelley \& Weaver 1969; Bell \& Bliss 1980). Cold environments may strongly restrict various kinds of temperature-dependent physiological activities affecting photosynthesis, fertilization and reproduction. Low temperature also affects the activities of insect pollinators (Kevan \& Baker 1983; Totland 1994a), resulting in fewer opportunities for cross-pollination and therefore restricted gene flow. Thus, biotic and abiotic factors may greatly affect sexual reproduction and seed production, especially in plants inhabiting areas in front of glaciers. This study examines the effects of cross-pollination and artificial warming on seed production. Its purpose was to clarify how these factors affect seed-setting success in a circumpolar plant species, Dryas octopetala L., in front of Brøggerbreen (Brøgger Glacier), near Ny-Ålesund, Svalbard. The intensity of reindeer's grazing on Dryas flowers was also examined to determine its influence on the reproduction of the plant. Reindeer frequently forage not only on grasses, sedges and lichens 
(Jefferies et al. 1992) but also on the flowers of $D$. octopetala, Saxifraga oppositifolia, S. nivalis and Silene acaulis (Wada, personal obs.).

Gender expression of some plant species varies along an environmental gradient and among habitat conditions (e.g. Kudo 1997). Under stressful or resource-limited conditions for reproduction, smaller-sized plants have a higher rate of success in reproducing through the male function than through the female function (Lovett Doust \& Lovett Doust 1988; Klinkhamer \& de Jong 1993; Kudo 1993). In a preliminary survey, it was found that $D$. octopetala had two types of flowers: hermaphrodite and male flowers (Wada et al. 1999). The present study reports on the phenological and size differences between hermaphrodite and male flowers, as well as the gender variations within hermaphrodite flowers in relation to flower size.

This study aims to clarify: 1) the number of flowers of $D$. octopetala which are grazed or survive during the flowering period; 2) the effect of grazing animals on the spatial distribution of Dryas flowers; 3) the effect of flower size on gender expression or allocation to female function; 4) the effect of factors such as pollen limitation and low temperature during a flowering period on seed production. Finally, this paper discusses factors affecting seed-setting success from the onset of flowering to the fruiting stage.

\section{Materials and methods}

\section{Study site}

The study site was located ca. $1.5 \mathrm{~km}$ from the edge of Brøggerbreen (Brøgger Glacier) and ca. $0.5 \mathrm{~km}$ from Kongsfjorden, near $\mathrm{Ny}$-Ålesund $\left(78^{\circ} 55^{\prime} \mathrm{N}, 11^{\circ} 56^{\prime} \mathrm{E}\right)$, Svalbard. The monthly average temperatures of June, July and August 1996 were $1.9^{\circ} \mathrm{C}, 3.8^{\circ} \mathrm{C}$ and $3.5^{\circ} \mathrm{C}$, respectively (data from Norwegian Polar Institute). In early July 1996, a $10 \mathrm{~m} \times 50 \mathrm{~m}$ plot was established on a ridge. This plot was dominated by $D$. octopetala but included Salix polaris, Saxifraga oppositifolia, Silene acaulis, Oxyria digyna, Polygonum viviparum and bryophytes.

\section{Plant material (Dryas octopetala L.)}

D. octopetala is widely distributed in the low
Arctic in Alaska (McGraw 1985) and Scandinavia and in the high Arctic in Svalbard, Norway, Greenland, and Russia (Hultén 1959; Rønning 1969, 1996). This plant forms a cushion on the ground, and has one flower per terminal shoot. However, the cushion form is not always welldefined, and it was difficult to determine individual plants in the plot used in this study. The bowlshaped flowers show sun-tracking behaviour (flower heliotropism), resulting in high temperature in the gynoecium as compared to ambient temperature (Kjellberg et al. 1982). This may be necessary for D. octopetala to produce seeds in cold environments, suggesting a species sensitive to solar radiation and temperature in terms of its reproduction.

\section{Flowering phenology and grazing pattern}

In the plot, 300 shoots $(271$ flower buds and 29 flowers) of $D$. octopetala were randomly selected and tagged on 11 July 1996. They were observed every day from the onset of flowering to the end, and the phenology of hermaphrodite and male flowers was recorded, as was the number of grazed flowers. Because reindeer grazed on the Dryas flowers but not the stalks (peduncles), the grazed flowers could be recorded by the remaining flower stalks on the shoots.

On 10 August, a $4 \mathrm{~m} \times 4 \mathrm{~m}$ quadrat was established in the study plot. The quadrat was divided into $640.5 \mathrm{~m} \times 0.5 \mathrm{~m}$ subquadrats. Grazed and non-grazed flowers and the leaf cover of $D$. octopetala were mapped in each subquadrat to clarify the effect of grazing on the spatial distribution of Dryas flowers. The spatial pattern of initial flowers and grazed flowers was analysed using Morishita's $I \delta$ index (Morishita 1959), with the following formula:

$$
I \delta=n \sum_{i=1}^{n} x i(x i-1) / \mathrm{N}(\mathrm{N}-1),
$$

where $n$ is the number of subquadrats of a given size (e.g. $640.5 \mathrm{~m} \times 0.5 \mathrm{~m}$ quadrats), $x i$ is the number of flowers in a $i$ th subquadrat, and $\mathrm{N}$ is the total number of flowers (in the $4 \mathrm{~m} \times 4 \mathrm{~m}$ quadrat). $I \delta>1$ shows clumped distribution; $I \delta=1$, random distribution; $I \delta<1$, uniform distribution. $I \delta$ was calculated at a different subquadrat size; $0.25 \mathrm{~m}^{2}, 1 \mathrm{~m}^{2}$ and $4 \mathrm{~m}^{2}$ (for details see Morishita $1959,1962)$. The significance of $I \delta>1$ or $<1$ was tested by using $F$ test $(d f=n-1, \infty)$, calculated 
with the following formula:

$$
F=[I \delta(\mathrm{N}-1)+n-\mathrm{N}] /(n-1) .
$$

\section{Gender variation of Dryas flowers}

Twenty-four hermaphrodite flowers and 20 male flowers were randomly collected in the study plot in late July 1996. In each flower, the length (L) and width (W) of four petals per flower were measured. Individual petal area (PA) was calculated with the following formula:

$$
\mathrm{PA}=(\mathrm{L} \times \mathrm{W}) \times \pi \times 0.25,
$$

where each petal was estimated as an ellipse shape. After that, each flower was dissected into petal, androecium, gynoecium (hermaphrodite flowers), calyx and receptacle and dried for 48 hours at $80 \mathrm{C}$. The dry weight of these parts was measured and compared between hermaphrodite and male flowers.

Furthermore, to clarify a variation of sex allocation based on dry weight within hermaphrodite flowers, "femaleness" was calculated with the following formula:

$$
\text { Femaleness }=\mathrm{GW} /(\mathrm{GW}+\mathrm{AW}) \text {, }
$$

where GW is the dry weight of the gynoecium, and AW is that of the androecium (cf. Lloyd 1980). In this study, femaleness was used as an indicator of the reproductive effort of female function, and the relationship between femaleness and the flower size (dry weight) was analysed to determine whether femaleness is size-dependent.

\section{Effects of cross-pollination and artificial warming on seed production}

To determine whether seed production is restricted by pollen limitation or by low temperature, four treatments were conducted within the plot: 1) hand-pollination (HP), in which the gynoecium of Dryas flowers was supplied with pollen collected from the other five flowers $(n=25$ flowering shoots); 2) netting (N), in which a flowering shoot was covered with fine polyester netting (mesh size $\left.<1 \mathrm{~mm}^{2} ; n=15\right)$ to exclude any pollen-transporting insects; 3) warming (W), in which a flowering shoot was artificially warmed using a small greenhouse made of steel wire and vinyl sheeting ( $n=15$ ); and 4) hand-pollination and warming (WHP, $n=15$ ). The fine polyester nets and small greenhouses were set up on mature flower buds of
Dryas shoots from 16 to 20 July. In HP and HPW treatments, Dryas flower buds were emasculated on 20 July, and cross-pollination was conducted when those petals completely opened on 24 July. On 4 August, all nets and greenhouses were removed when all petals dropped off the flowers. Flower buds occurring near the greenhouses were tagged as controls $(n=25)$. On 20 August, these shoots were collected, and the seed-set per flowering shoot was compared among treatments. Following Wookey, Parsons et al. (1993), "seedsetting" is defined as the number of fruiting shoots having one or more mature seeds with welldeveloped feathery styles beyond the extent of the sepals, divided by the number of flowering shoots in each treatment.

To confirm the warming effect of the small greenhouses, a small temperature data-logger was set up (StowAway TidbiT, Onset Computer Corporation) inside and outside the greenhouse on the ground. This measured the temperature at two-minute intervals from 1 to 8 August 1997.

\section{Results and discussion}

\section{Grazing pattern and flowering phenology}

In the tagged Dryas flowers, the onset of flowering occurred from early to late July. Out of 300 reproductive shoots, $10(3.3 \%)$ buds were immature and did not bloom. One hundred (33.3\%) flower buds and flowers were grazed by reindeer: 23 in the pre-flowering stage (flower bud), 73 in the flowering stage, and 4 in the post-flowering stage. Reindeer tended to forage on Dryas flowers on the 5th day ( \pm SD 2 days), ranging from the 1 st to the 11th day $(n=69)$, after their petals opened. Thus, $110(36.7 \%)$ shoots failed to produce offspring before producing seeds and fruits.

Grazing by reindeer had a strong impact on the spatial distribution of Dryas flowers. As shown in Figs. 1 and 2, Dryas flowers were initially distributed in small, clumped patches at 0.25 and $1 \mathrm{~m}^{2}$ scales. However, grazed flowers were more aggregated than initial flowers in both scales, indicating density-dependent predation on Dryas flowers. Because a high density of flowers results in a high probability of cross-pollination by attracting pollinators (Thomson et al. 1982; Sih \& Baltus 1987; Totland 1994a), a densitydependent grazing pattern might not only directly 


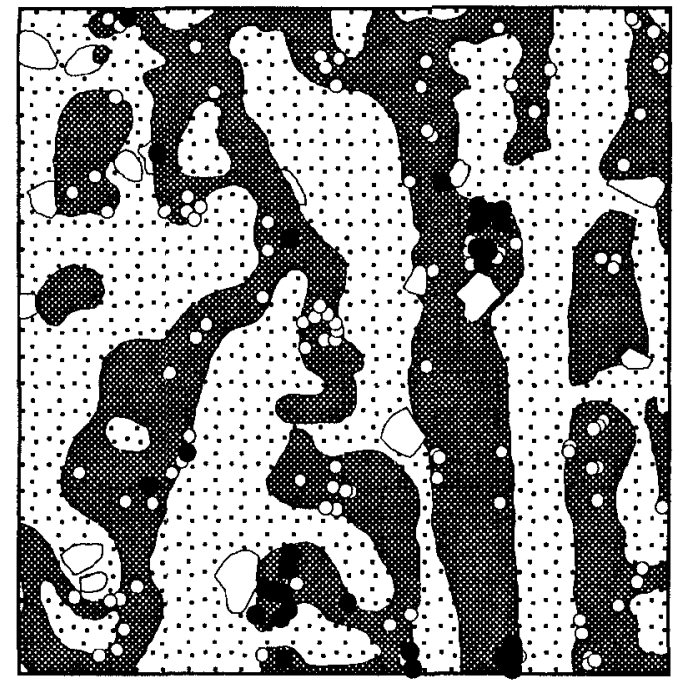

$0.5 \mathrm{~m}$

Fig. 1. Spatial distribution of Dryas flowers $(-$ grazed flowers, $n=30 ; O=$ non-grazed flowers, $n=110$ ) in the $4 \mathrm{~m} \times 4 \mathrm{~m}$ quadrat. Grey-shaded area $=$ leaf cover of Dryas octopetala $;$ dotted area $=$ gravel $($ bare ground).

decrease the number of flowers potentially producing seeds and fruits but also indirectly reduce a chance of out-crossing in the remaining (nongrazed) flowers.

\section{Phenological and size differences between hermaphrodite and male flowers and gender variation within hermaphrodite flowers}

In the tagged flower buds and flowers, 190 shoots succeeded in flowering without being grazed. However, $45(23.7 \%)$ flowers did not have any gynoecium; that is, they were male flowers. The number of male flowers versus hermaphrodite flowers tended to be slightly higher in late flowering shoots than in early flowering shoots (Fig. 3). When 190 shoots were divided into two groups, early flowering shoots (defined as those which began to flower on or before 15 July) and late flowering shoots (after 15 July), the ratio of male flowers (22) to hermaphrodite flowers (90) was 0.24 in early flowering shoots and 0.42 (23/ 55) in late flowering shoots. In later flowering shoots or plants, the growing period may be insufficient for the completion of seed maturation, resulting in reduced seed production or low seedset (Spira \& Pollack 1986; Kudo 1991; Totland

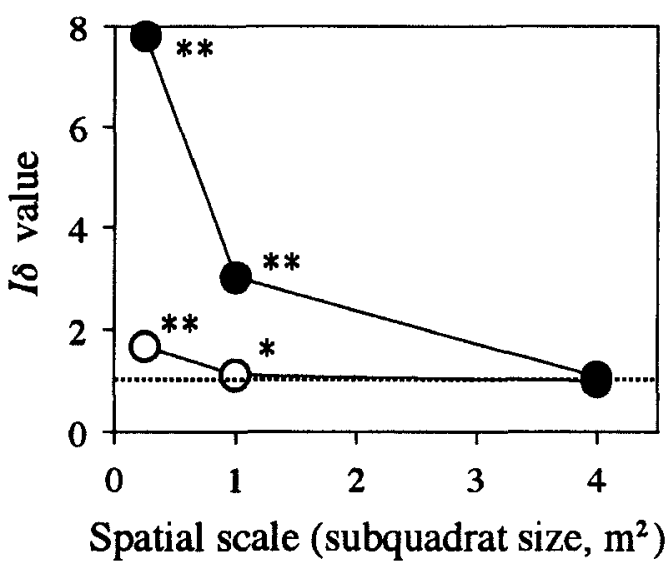

Fig. 2. Morishita's $I \delta$ values for initial flowers $(O)$ and grazed flowers (O) at the three spatial scales: $0.25 \mathrm{~m}^{2}, 1 \mathrm{~m}^{2}$ and $4 \mathrm{~m}^{2}$. The broken line shows $I \delta=1$ (random distribution). ${ }^{* *}=P<0.01 *^{*}=P<0.05$.

1994b, 1997). The high ratio of male flowers to hermaphrodite flowers in later flowering shoots may reflect that reproduction through the female function is difficult for late flowering Dryas flowers due to the short growing period. This selection pressure might strongly act on Dryas flowers, resulting in a higher occurrence of male flowers in later flowering shoots. Philipp et al. (1990) observed that $D$. integrifolia also had hermaphrodite and male flowers, and male flowers appeared later than hermaphrodite flowers in a population in Greenland. However, because phenological differences vary among populations

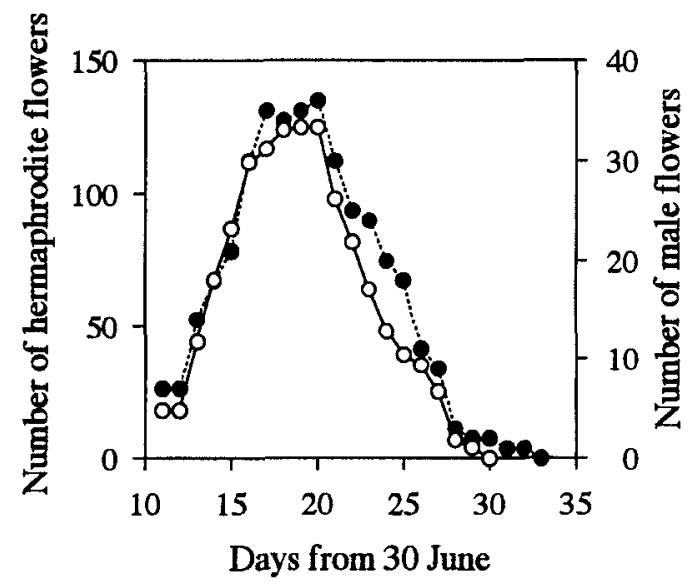

Fig. 3. Flowering phenology of hermaphrodite flowers $(O$, $n=145)$ and male flowers $(\mathbf{O}, n=45)$. 


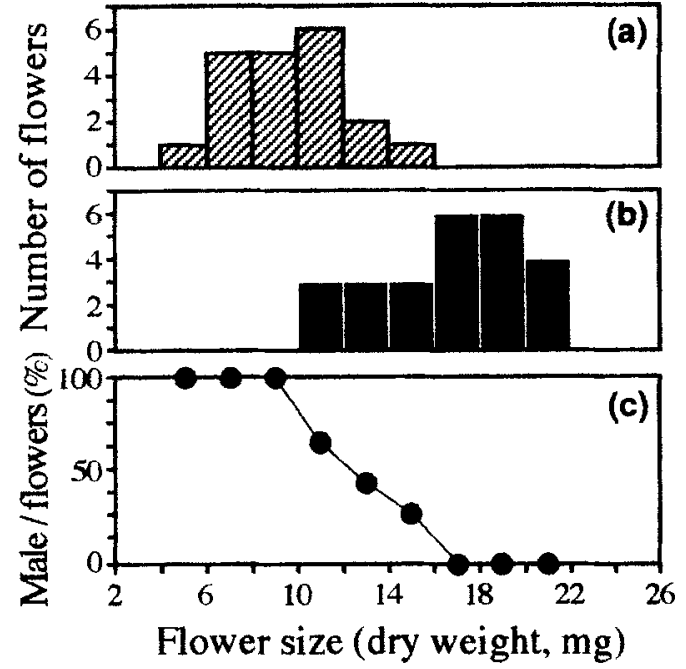

Fig. 4. (a) Flower size (dry weight) of male flowers and (b) hermaphrodite flowers, and (c) the frequency of male/all flowers $(\%)$ in relation to the flower size.

(Philipp et al. 1990), further information concerning several populations is required.

Dry weight was significantly lower in male flowers (mean $\pm \mathrm{SD}$ : $9.6 \pm 2.5 \mathrm{mg}, n=20$ ) than in hermaphrodite flowers $(16.9 \pm 2.3 \mathrm{mg}, n=24$, see Fig. 4). Male flowers had a smaller petal area and lighter petal and androecium weight than hermaphrodite flowers (Table 1), suggesting lower investments to reproduction through male flowers. All flowers with a dry weight under $10 \mathrm{mg}$ were male shoots, while all flowers having a dry weight over $16 \mathrm{mg}$ were hermaphrodite shoots. Flowers ranging from $10 \mathrm{mg}$ to $16 \mathrm{mg}$ in dry weight were composed of both male and hermaphrodite shoots (Fig. 4). According to the frequency distribution of dry weight, male flowers did not completely

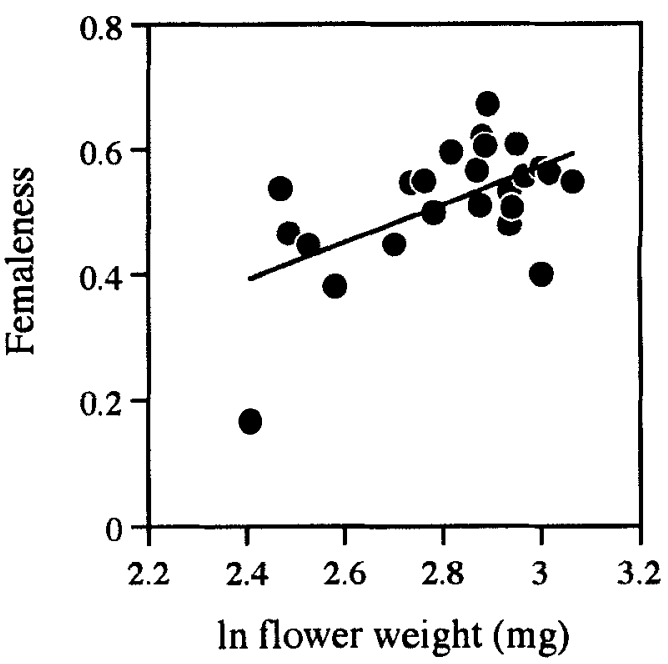

Fig. 5. Relationship between flower size (ln flower weight $=X$ ) and femaleness $(Y)$ in hermaphrodite flowers of Dryas octopetala $(Y=0.306 X-0.345, r=0.573, n=24, P=0.0028)$.

segregate from hermaphrodite ones; rather, the gender sequentially changed from a male- to female- (hermaphrodite-) biased expression as flower size increased (Fig. 4). Moreover, dryweight allocation to the female function (femaleness) varied even within hermaphrodite flowers, and femaleness was positively correlated with flower size to a significant degree (Fig. 5). Thus, smaller flowers tended to allocate dry-matter investments into male organs (androecium) more than into female organs (gynoecium), as compared to larger flowers. With respect to size-dependence, this result supports a previous study by Kudo (1993) in Anemone debilis Fish.

According to Molau (1993), D. octopetala has been recognized as a typical gynodioecious plant

Table 1. Size differences between hermaphrodite $(n=24)$ and male flowers $(n=20)$ of Dryas octopetala (mean $\pm \mathrm{SD}$ ). The differences were analysed with Student's $t$-test.

\begin{tabular}{lcccc}
\hline & Hermaphrodite & Male & $t$-value & $P$ \\
\hline Petal area $\left(\mathrm{mm}^{2}\right)^{*}$ & $43.2 \pm 9.9$ & $29.7 \pm 11.1$ & 4.24 & 0.0001 \\
Petal weight $(\mathrm{mg})$ & $5.9 \pm 1.6$ & $3.7 \pm 1.2$ & 5.33 & $<0.0001$ \\
Androecium weight $(\mathrm{mg})$ & $2.3 \pm 0.5$ & $1.8 \pm 0.6$ & 3.66 & 0.0007 \\
Gynoecium weight $(\mathrm{mg})$ & $2.6 \pm 0.9$ & - & - & - \\
Calyx and receptacle & $6.0 \pm 1.0$ & $4.2 \pm 1.1$ & 5.92 & $<0.0001$ \\
(mg) & & & & \\
Flower weight (mg) & $16.9 \pm 2.3$ & $9.6 \pm 2.5$ & 8.74 & $<0.0001$ \\
\hline
\end{tabular}

*Individual (mean) petal area per flower. 
species, composed of a mixture of hermaphrodite and purely female shoots. However, such a gynodioecy type was not found in this study, but male shoots in addition to perfect hermaphrodite shoots on the same cushions (individuals) were frequently observed. This suggests an andromonoecy or androdioecy of D. octopetala, as reported by Philipp et al. (1990) for D. integrifolia. Although further detailed studies are needed to clarify the variation of sex expression in Dryas species in relation to various environmental conditions, $D$. octopetala might have high phenotypic and genetic variations for floral sex allocation, as shown in this study.

In Ny-Ålesund, Wookey, Parsons et al. (1993) and Wookey, Robinson et al. (1995) examined seed-sets of $D$. octopetala in various simulated environments. However, it was unclear whether a seed-set was obtained by the number of fruiting shoots divided by the number of flowering shoots minus the number of male flowering shoots. If these studies did not exclude the number of male flowering shoots, they would have underestimated the actual seed-set. It is important to examine the variations of the number of male flowers among experimental treatments and/or from year to year when assessing the differences of the seed-sets under various environmental conditions.

\section{Effects of cross-pollination and artificial warming on seed production}

The small greenhouses increased the mean temperature by $\mathrm{ca} .1 .3^{\circ} \mathrm{C}$, maximum $8.7^{\circ} \mathrm{C}$ and minimum $-1.4^{\circ} \mathrm{C}$, as compared to the outside temperature from 1 to 8 August $1997(n=5040$ measuring points, Fig. 6 ). The results of pollination and warming effects on seed-set are shown in Fig. 7. In this study, in the year 1996, Dryas flowering shoots did not produce any seeds in the control shoots $(n=25)$ or in 145 tagged hermaphrodite flowering shoots. The cross-pollinated and net-covered shoots showed $8 \%$ and $6 \%$ seed-set, respectively, while the artificially warmed shoots showed $60 \%$ seed-set regardless of cross-pollination or autodeposition (internal transfer of pollen from anthers to stigma without any external vector). This shows the self-compatibility of $D$. octopetala in a population in $\mathrm{Ny}$-Ålesund, as previously reported by Molau (1993) in a natural population in Latnjajaure $\left(68^{\circ} 22^{\prime} \mathrm{N}, 18^{\circ} 29^{\prime} \mathrm{E}\right)$, in northernmost Sweden. The net-covered flowering shoots succeeded in producing a small portion of
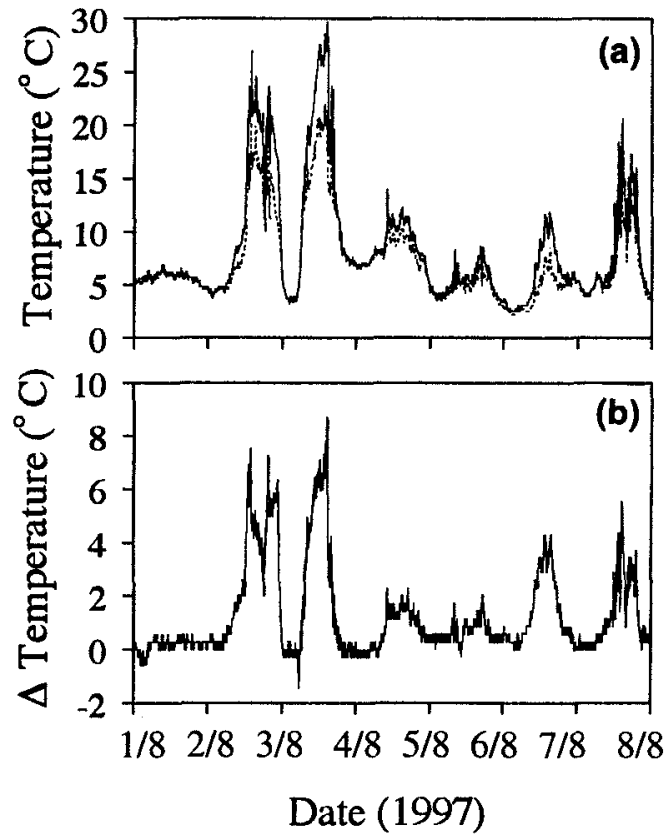

Fig. 6. (a) Temperature ( ${ }^{\circ} \mathrm{C}$ ) inside (solid line) and outside (dashed line) the small greenhouse, and (b) the difference $(\triangle$ Temp.).

seeds, probably because the fine net cover increased temperature slightly by reducing wind. Wookey, Parsons et al. (1993) also demonstrated that $D$. octopetala showed $60 \%$ seed-set by an artificial warming treatment using open-topped

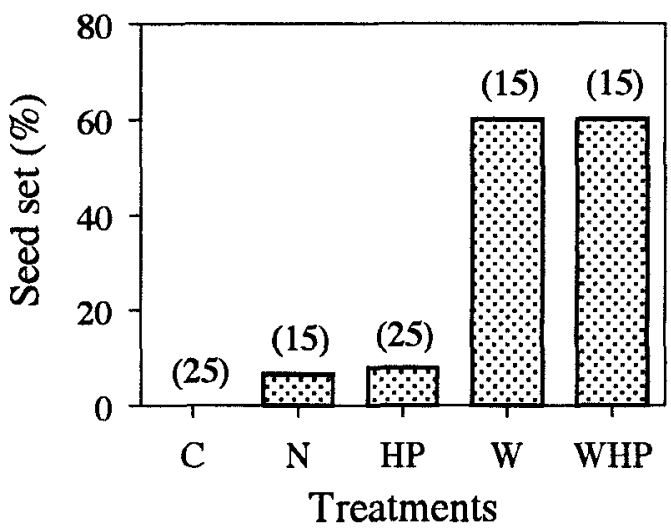

Fig. 7. Effects of pollinator exclusion (netting, N), crosspollination (hand pollination, HP), artificial warming (W), combination of cross-pollination and artificial warming (WHP) on seed-set (\%) of Dryas flowers. C shows control. Numerals in parentheses on the bars show number of samples. 
polythene tents, while there was no seed-set in the control in Ny-Alesund. The duration of artificial warming by small greenhouses was shorter (only in the flowering period) and the degree of increased temperature was smaller in this study than in that by Wookey, Parsons et al. (1993). However, a higher seed-set in the short-term artificially warmed shoots indicates that temperature during a flowering period greatly affects seedsetting success. Furthermore, it suggests that temperature-dependent physiological processes such as pollen germination, pollen tube elongation, and fertilization may be strongly restricted in a natural population of $D$. octopetala near Brøggerbreen. Therefore, it is necessary to examine pollen activity and fertilization under various temperature conditions to elucidate temperaturedependent physiological traits.

\section{Concluding remarks}

This study demonstrates that grazing on flower buds and flowers, gender variation in relation to length of growing season and flower size, and (in the flowering period) low temperature rather than pollinator limitation appear to affect strongly the seed-setting success of D. octopetala. In this study, the warming effects on sex allocation to the female function in hermaphrodite flowers, seed viability (germinability), seedling establishment, and survival were not examined. However, these are very important parameters to predict the population dynamics of D. octopetala or its succession around or in front of glaciers under warmed conditions. In recent studies, Wookey, Robinson et al. (1995) and Welker et al. (1997) reported that the phenological development of $D$. octopetala is accelerated under experimentally warmed conditions. This finding corresponds with a lengthening of the growing season in autumn, greater degrees of seed-set. and a higher potential of colonization of the bare ground due to heavier seed weight and then higher germinability. For this reason, long-term studies are necessary which include manipulated experiments and the monitoring of the growth and reproduction of many tundra plants in the field. Taking into consideration both abiotic and biotic factors, such as population dynamics of insect pollinators and grazing animals, such studies would serve to clarify the changes of Arctic plant populations and ecosystems under global climatic warming.

Acknowledgements. - I am very grateful to the staff at the Norwegian Polar Institute, KBKC and NIPR for their support during my research in $\mathrm{Ny}$-Ålesund. I also thank H. Kanda and G. Kudo for their encouragement throughout this study, and Y. Bekku and T. Nakatsubo for their assistance in the field work. This study was supported by a Japanese Ministry of Education, Science and Culture Grant-in-Aid for International Scientific Research (No. 06044224), Project "Ecosystem Change at the Glacier-Edge Areas in the Arctic."

\section{References}

Bell, K. L. \& Bliss, L. C. 1980: Plant reproduction in a high Arctic environment. Arctic Alp. Res. 12, 1-10.

Hultén, E. 1959: Studies on the genus Dryas. Svensk Bot. Tidskr. 53, 507-547.

Jefferies, R. L., Svoboda, J., Henry, G., Raillard, M. \& Ruess, R. 1992: Tundra grazing systems and climatic change. In F. S. Chapin III et al. (eds.): Arctic ecosystems in a changing climate: an ecophysiological perspective. Pp. 39-412. California: Academic Press.

Kelley, J. J. \& Weaver, D. F. 1969: Physical processes at the surface of the Arctic tundra. Arctic 22, 425-437.

Kevan, P. G. \& Baker, H. G. 1983: Insects as flower visitors and pollinators. Annu. Rev. Entom. 28, 407-453.

Kjellberg, B., Karlsson, S. \& Kerstensson, I. 1982: Effects of heliotropic movements of flowers of Dryas octopetala L. on gynoecium temperature and seed development. Oecologia 54 , 10-13.

Klinkhamer, P. G. L. \& de Jong, T. J. 1993: Phenotypic gender in plants: effects of plant size and environment on allocation to seeds and flowers in Cynoglossum officinale. Oikos 67,8186.

Kudo, G. 1991: Effects of snow-free period on the phenology of alpine plants inhabiting snow patches. Arct. Alp. Res. 23, $436-443$.

Kudo, G. 1993: Size-dependent resource allocation pattern and gender variation of Anemone debilis Fish. Plant Species Biol. $8,29-34$.

Kudo, G. 1997: Sex expression and fruit set of an andromonoecious herb. Peucedanum multivittatum (Umbelliferae) along a snowmelt gradient. Opera Bot. 32, 121-128.

Lloyd, D. J. 1980: Sexual strategies in plants. III. A quantitative method for describing the gender in plants. N. Z. J. Bor. 18 , 103-108.

Lovett Doust, J. \& Lovett Doust, L. 1988: Sociobiology of plants: an emerging synthesis. In J. Lovett Doust \& L. Lovett Doust (eds.): Plant reproductive ecology. Paterns and strategies. Pp. 5-29. New York: Oxford University Press

McGraw, J. B. 1985: Environmental ecology of Dryas octoperala ecotypes. III. Environmental factors and plant growth. Arct. Alp. Res. 17, 229-239.

Maxwell, B. 1992: Arctic climate: potential for change under global warming. In F. S. Chapin III et as, (eds.); Arctic ecosystems in a changing climate: an ecophysiological perspective. Pp. 11-34. California: Academic Press. 
Molau, U. 1993: Relationships between flowering phenology and life history strategies in tundra plants. Arct. Alp. Res. 25, $391-402$.

Morishita, M. 1959: Measuring of dispersion of individuals and analysis of the distributional patterns. Memoir Faculty of Science Kyushu University Series E (Biology) 2, 215-235.

Morishita, M. 1962: $1 \delta$-index, a measure of dispersion of individuals. Res. Popul. Ecol. 4, 1-7.

Philipp, M., Böcher, J., Mattsson, O. \& Woodell, S. R. J. 1990: A quantitative approach to the sexual reproductive biology and population structure in some Arctic flowering plants: Dryas integrifolia, Silene acaulis and Ranunculus nivalis. Medd. Gronland, Biosci. 34, 1-60.

Rønning, O. I. 1969: Features of the ecology of some Spitzbergen plant communities. Arct. Alp. Res. 1, 29-44.

Rønning, O. I. 1996: The flora of Svalbard. Pp. 66-67. Oslo: Norwegian Polar Institute.

Sih, A. \& Baltus, M.-S. 1987: Patch size, pollinator behavior, and pollinator limitation in catnip. Ecology 68, 1679-1690.

Spira, T. P. \& Pollack, O. D. 1986: Comparative reproductive biology of alpine biennial and perennial gentians (Gentiana: Gentianaceae) in California. Am. J. Bot. 73, 39-47.

Thomson, J. D., Maddison, W. P. \& Plowright, R. C. 1982: Behavior of bumble bee pollinators of Aralia hispida Vent. (Araliaceae). Oecologia 54, 326-336.
Totland, $\emptyset$. 1994a: Influence of climate, time of day and season, and flower density on insect flower visitation in alpine Norway. Arct. Alp. Res. 26, 66-71.

Totland, $\varnothing .1994 \mathrm{~b}$ : Intraseasonal variation in pollination intensity and seed-set in an alpine population of Ranunculus acris in southwestern Norway. Ecography 17, 159-165.

Totland, $\varnothing .1997$ : Effects of flowering time and temperature on growth and reproduction in Leontodon autumnalis var. taraxaci, a late-flowering alpine plant. Arct. Alp. Res. 29, 285-290.

Wada, N., Kudo, G. \& Kojima, S. 1999: Gender variation of Dryas octopetala along snowmelt and latitudinal gradients in the subarctic and the high Arctic. Polar Biosci. 12, 87-99.

Welker, J. M., Molau, U., Parsons, A. N., Robinson, C. H. \& Wookey, P. A. 1997: Responses of Dryas octopetala to ITEX environmental manipulations: a synthesis with circumpolar comparisons. Global Change Biol. 3, 61-73.

Wookey, P. A., Parsons, A. N., Welker, J. M., Potter, J. A., Callaghan, T. V., Lee, J. A. \& Press, M. C. 1993: Comparative responses of phenology and reproductive development to simulated environmental change in subArctic and high Arctic plants. Oikos 67, 490-502.

Wookey, P. A., Robinson, C. H., Parsons, A. N., Welker, J. M., Press, M. C., Callaghan, T. V. \& Lee, J. A. 1995: Environmental constraints on the growth, photosynthesis and reproductive development of Dryas octopetala at a high Arctic polar semi-desert, Svalbard. Oecologia 102, 478-489. 